\title{
ИЗМЕНЕНИЯ В СТРУКТУРЕ РОССИЙСКИХ ДОМОХОЗЯЙСТВ В 1994-2013 ГГ. (СТАТИСТИЧЕСКИЙ
} АНАЛИЗ) *

\author{
КСЕНИЯ АБАНОКОВА
}

\begin{abstract}
Сравнение семейной структуры населения и состава домохозяйств - важная и актуальная тема исследования. Большинство российских работ основано на использовании материалов переписей населения и выборочных обследований, которые дают одномоментные «срезы» населения и не предназначены для динамического наблюдения. Динамический анализ позволяет адекватно интерпретировать наблюдаемые тенденции и долговременные сдвиги в структуре домохозяйств.

В статье исследуются перемещения индивидов между разными типами домохозяйств $и$ продолжительность пребывания в домохозяйстве данного типа методом анализа дожития с использованием функции дожития Каплана-Мейера. Анализ выполнен на основе данных панельного обследования «Российский Мониторинг экономического положения и здоровья населения» (РМЭЗ-ВШЭ) за 1994-2013 г2.

Данные РМЭЗ-ВШЭ предоставляют уникальную возможность наблюдения за одними и теми же домохозяйствами в течение длительного времени, а также дают возможность фиксировать все смены состояния домохозяйства и время этих событий. Применяемые статистические методы анализа позволяют преодолеть ограничения, связанные со спецификой панельных данных РМЭЗ-ВШЭ, а также оценить вероятность перехода домохозяйств с учетом продолжительности пребывания индивидов 8 домохозяйствах и факторов, влияющих на эту вероятность.
\end{abstract}

Несмотря на то, что наша статья является описательной, поскольку мы не изучаем причины, которые могут привести к наблюдаемому распределению домохозяйств, в силу их многообразия и сложности интерпретаџии, она дает основу для дальнейшего аналитического исследования причин трансформации домохозяйств.

Ключевые слова: структура домохозяйств, панельные данные, анализ дожития, метод КапланаМейера, РМЭЗ.

\section{ВВЕДЕНИЕ}

Интерес к изучению процессов формирования и разделения российских домохозяйств объясняется значительной подвижностью их структуры во времени. Многочисленные исследования подчеркивают нестабильность разных типов домохозяйств, но рассматривают структуру как моментный показатель. Динамический анализ дает основу для адекватной интерпретации наблюдаемых тенденций и долговременных сдвигов в структуре домохозяйств, однако сопряжен с рядом трудностей, которые в первую очередь вызваны ограничениями данных.

КСЕНИЯ РУСЛАНОВНА АБАНОКОВА. ЦЕНТР ТРУДОВЫХ ИССЛЕДОВАНИЙ НАЦИОНАЛЬНОГО ИССЛЕДОВАТЕЛЬСКОГО УНИВЕРСИТЕТА «ВЫСШАЯ ШКОЛА ЭКОНОМИКИ». РОССИЯ. E-mail: kabanokova@hse.ru

СТАТЬЯ ПОСТУПИЛА В РЕДАКЦИЮ В ДЕКАБРЕ 2014 Г.

* ДАННАЯ РАБОТА ЯВЛЯЕТСЯ РЕЗУЛЬТАТОМ ИССЛЕДОВАТЕЛЬСКОГО ПРОЕКТА, РЕАЛИЗОВАННОГО В РАМКАХ ПРОГРАММЫ ФУНДАМЕНТАЛЬНЫХ ИССЛЕДОВАНИЙ НИУ ВШЭ. ОНА ОТРАЖАЕТ МНЕНИЕ АВТОРА И НЕ ЯВЛЯЕТСЯ ОФИЦИАЛЬНОЙ ПОЗИЦИЕЙ НИУ ВШЭ ИЛИ ДРУГИХ, СВЯЗАННЫХ С ЭТИМ УЧРЕЖДЕНИЕМ, ОРГАНИЗАЦИЙ. 
Большинство российских работ, посвященных исследованию домохозяйств, основано на использовании материалов переписей населения и выборочных обследований, которые дают одномоментные «срезы» населения и не предназначены для динамического наблюдения. В ряде исследований используются данные обследования «Поколение и гендер», содержащие сведения о семейных взаимоотношениях, но имеющие ограниченную временную глубину ${ }^{1}$ Среди авторов, которые в последнее время занимались вопросами прогнозирования и моделирования семейной структуры российского населения, можно выделить работы С.В. Захарова и Л.М. Прокофьевой [Захаров 2006, 2007; Прокофьева 2007]. Значительный вклад в изучение процессов формирования семьи и ее эволюции внес в свое время А.Г. Волков, разграничив понятия семьи и домохозяйства и исследовав изменение семейной структуры советского населения за относительно длительный период - сорок лет (а по городскому населению - за пятьдесят с лишним лет) [Волков 1986].

Трудности в изучении процессов формирования и разделения домохозяйств также связаны с тем, что на разных этапах развития домохозяйства такие демографические события, как рождение, смерть, вступление в брак и развод, смена места жительства, происходят в определенный момент времени и с разной интенсивностью. В то же время интенсивность этих событий зависит от длительности пребывания в них.

Цель данной работы - определить наиболее вероятные переходы между разными типами домохозяйств с учетом продолжительности пребывания индивидов в этих домохозяйствах. Мы отвечаем на следующие вопросы: какова интенсивность переходов домохозяйств, а также как эта интенсивность связана с разными характеристиками домохозяйства. Несмотря на то, что большинство переходов осуществляется домохозяйствами в результате демографических событий, мы не изучаем причины, которые могут привести к наблюдаемому распределению домохозяйств в силу их многообразия и сложности интерпретации. Например, смертность и рождаемость могут приводить как к уменьшению/увеличению размера домохозяйства, так и к изменению его типа. Заключение брака или развод меняют тип и состав сразу нескольких домохозяйств. Помимо этого существует множество других процессов, происходящих в домохозяйстве и меняющих его структуру: покидание детьми своих родителей ради образования собственной семьи, усыновление/удочерение, отказ от родительских прав, родственный обмен, связанный с экономическими выгодами участвующих в обмене домохозяйств.

Используя данные панельного обследования Российского Мониторинга экономического положения и здоровья населения (РМЭЗ-ВШЭ) за 1994-2013 гг., мы проанализировали изменения в структуре российских домохозяйств с помощью моделей дожития. РМЭЗ-ВШЭ предоставляет уникальную возможность наблюдения за одними и теми же домохозяйствами в течение длительного времени, а также дает возможность фиксировать все смены состояния домохозяйства и время этих событий. Модели дожития позволяют преодолеть ограничения, связанные с неравномерностью включения домохозяйств в панель РМЭЗ-ВШЭ и с выбытием домохозяйств из обследования.

${ }^{1}$ На 2013 г. было проведено три волны обследования «Поколения и гендер» с трехлетним интервалом. 
Наша работа расширяет предыдущие демографические исследования по изучению российских домохозяйств, а информация об интенсивности демографических изменений будет полезна при исследовании факторов социально-демографического поведения семьи.

Работа состоит из пяти частей. Мы начинаем с описания существующих исследований, посвященных анализу факторов изменения структуры российских домохозяйств, далее переходим к используемым данным и классификации домохозяйств. В третьей части мы представляем описательный анализ основных изменений в распределении домохозяйств по данным РМЭЗ-ВШЭ. В четвертой части представлена методология статистического анализа изменений структуры домохозяйства с использованием моделей дожития. В пятой части представлены результаты. Обсуждение полученных результатов и выводы приведены в заключении.

\section{ОБЗОР ЛИТЕРАТУРЫ}

В современной демографической литературе широко исследована связь демографических событий с показателями возраста, пола, религии, образования, дохода и др.

Наибольшее внимание уделяется изучению факторов рождаемости и возможностей ее прогнозирования. Т.М. Малева и О.В. Синявская по данным первой волны обследования «Поколение и гендер» за 2004 г. оценили влияние различных факторов на вероятность рождения детей в течение последних трех лет, предшествующих опросу. Результаты показали, что проживание в городе, отсутствие брачного партнера и высшее образование женщины снижают вероятность рождения детей, в то время как молодой возраст, занятость на рынке труда, обеспеченность жильем и исламское вероисповедание женщины повышают вероятность рождения [Малеева, Синявская 2007]. По этим же данным Е.Б. Головляницина обнаружила значимое влияние социально-психологических факторов на намерение женщины родить ребенка [Головяницина 2007]. Используя данные за 2004 и 2007 г., О.В Синявская и А.О. Тындик оценивали влияние репродуктивных намерений женщин на рождаемость, а О.В. Синявская, С.В. Захаров и М.А. Карцева исследовали взаимосвязь между трудовыми и репродуктивными намерениями женщин [Синявская, Захаров, Карцева 2007; Синявская, Тындик 2009]. Согласно результатам, которые получили О.В Синявская и А.О. Тындик, помимо репродуктивных установок, вероятность рождения определялась партнерским статусом женщины и числом ранее рожденных детей, а также положительно зависела от проживания в сельской местности и отрицательно - от образования и возраста женщины. Я.М. Рощина и А.В. Бойков на панельных данных РМЭЗ-ВШЭ за 1994-2001 гг. выявили основные факторы, определяющие репродуктивное поведение женщины: возраст и число детей, удовлетворенность материальным положением, частота употребления алкоголя, экономическое положение региона [Рощина, Бойков 2005].

Немногочисленные исследования показывают, что трансформацию российских домохозяйств могут вызвать экономические факторы. Оценивая государственную политику поддержки семей с детьми на данных РМЭЗ-ВШЭ за 2004-2010 гг., Ф. Слонимчик и А.В. Юрко доказали, что рост дохода домохозяйства является ключевым фактором в принятии решения о рождении детей [Slonimczyk, Yurko 2014]. На примере двух недавних рецессий 1998 и 2008 г. 
К. Абанокова и М. Локшин по данным РМЭЗ-ВШЭ показали, что домохозяйство реагирует на снижение дохода увеличением своего размера [Abanokova, Lokshin 2015].

\section{ДАННЫЕ}

В качестве эмпирической базы исследования использованы данные репрезентативного обследования домохозяйств РМЭЗ-ВШЭ. РМЭЗ-ВШЭ представляет собой ежегодное панельное обследование индивидов и домохозяйств, которое началось в 1994 г. с 3975 домохозяйств и на 2013 г. насчитывало 8149 домохозяйств (в 1997 и 1999 гг. обследование не проводилось).

Поскольку дизайн выборки РМЭЗ заключался в выборке жилищ, структура полученных данных позволяет отследить не только конкретные домохозяйства и их членов на протяжении всех волн, но и новые домохозяйства в том же жилище, а также переехавшие домохозяйства в пределах населенного пункта. Для каждого года мы можем наблюдать, отличается ли тип домохозяйства, в котором проживает индивид, от предыдущего и последующего типа домохозяйства. В результате можно определить время, проведенное индивидом в домохозяйстве конкретного типа (длительность), а также момент перехода индивида из одного домохозяйства в другое.

Мы используем годовые данные за 1994-2013 гг. и панель за тот же период, которая включает в себя 17 волн. Панель насчитывает 18996 домохозяйств, которые были опрошены в 1994-2013 гг. (несбалансированная панель).

\section{Сравнение данных по домохозяйствам в обследованиях РМЭЗ-ВШЭ и переписях населения}

Для проверки репрезентативности данных РМЭЗ-ВШЭ по домохозяйствам мы сравнили микроданные с соответствующими показателями переписей за 2002 и 2010 г. и микропереписи за 1994 г. В таблице П-1 Приложения показано распределение домохозяйств по размеру. Общая тенденция заключается в снижении среднего размера домохозяйств, увеличении доли небольших домохозяйств (из одного-двух человек) и сокращении более крупных домохозяйств (из пяти человек). Исключением является лишь некоторое увеличение доли домохозяйств из шести и более человек по данным РМЭЗ-ВШЭ, хотя доля этих домохозяйств невелика.

В 1994 г. разница между РМЭЗ-ВШЭ и переписями населения была в диапазоне 0,6 3,4 процентных пункта, в 2002 г. она колебалась в районе 0,3 - 2,6 п.п., а в 2010 г. составила не более 5,8 п.п. Поскольку данные обследования РМЭЗ-ВШЭ подвержены стандартным ошибкам ${ }^{2}$, не следует ожидать идеального соответствия. Среди возможных причин отклонений в результатах могут быть различные подходы к учету домохозяйств, участвующих в обследовании. Тем не менее результаты сравнения говорят о хорошем соответствии между данными РМЭЗ-ВШЭ и переписей населения, что делает наш анализ репрезентативным.

\footnotetext{
2 Чтобы принять это во внимание, мы используем статистически значимые различия на 5\%-ном уровне.
} 


\section{Классификация домохозяйств}

Согласно определению РМЭЗ-ВШЭ под «домохозяйством» понимается группа людей, проживающих совместно и имеющих совместный бюджет. Мы используем термины «домохозяйство» и «семья» как синонимы, поскольку в большинстве домохозяйств индивиды связаны родственными отношениями. Для определения отношений между членами домохозяйства в РМЭЗ-ВШЭ используется «сетка родственных отношений», отражающая отношения между каждым членом домохозяйства и «референтным членом». Под «референтным членом домохозяйства» понимается лицо, «которое обладает наибольшей информацией о совершаемых семьей покупках и здоровье членов семьи» ${ }^{3}$. Мы использовали детальную информацию о родственных связях для классификации домохозяйств по типам.

В России накоплен богатый опыт разработки типологий семей в зависимости от пола, возраста, отношений родства и целей использования полученных данных. Основными принципами, которым должна отвечать классификация семей, является способность учитывать полную и неполную семью, структуру семьи по наличию поколений в ней, разные этапы демографического развития [Волков 1986]. Мы выделяем пять типов домохозяйств: одиночные домохозяйства, состоящие из референтного члена домохозяйства, проживающего отдельно; супружеские ${ }^{4}$ бездетные пары; неполные домохозяйства с детьми ${ }^{5}$, состоящие из одного взрослого родителя и детей; полные домохозяйства с детьми, состоящие из супружеской пары и детей ${ }^{6}$; расширенные домохозяйства, включающие хотя бы одного индивида, который не является ни супругом, ни ребенком референтного члена домохозяйства. Членами расширенных домохозяйств могут являться родственники (двоюродные братья и сестры, дяди и тети и др.) и не родственники референтного члена домохозяйства. Несмотря на то, что данная классификация является упрощенной по сравнению с предложенной А.Г. Волковым для демографического анализа семей, она позволяет учесть основные фазы развития семьи.

\section{ОПИСАТЕЛЬНЫЙ АНАЛИЗ}

За относительно короткий период в 19 лет произошли значительные изменения в структуре российских домохозяйств. Среднее число индивидов в домохозяйстве снизилось с 2,9 в 1994 г. до 2,7 в 2013 г. (рисунок 1). Резкий скачок среднего размера домохозяйства, зафиксированный в 2010 г., вероятно, связан с увеличением размера выборки РМЭЗ-ВШЭ в этой волне. Более подробный анализ домохозяйств по типам подтверждает основные тенденции в структуре российских домохозяйств. За рассматриваемый период произошел рост доли одиночных домохозяйств на $35 \%$, супружеских пар на $9 \%$ и расширенных домохозяйств на $11 \%$ (рисунок 2). До 2002 г. динамика неполных семей имела неустойчивый тренд, снизившись в результате на 20\% в 2013 г. по отношению к 1994 г. В то же время доля полных

\footnotetext{
${ }^{3}$ http://www.cpc.unc.edu/projects/rlms-hse/data/documentation/householddata

${ }^{4}$ В РМЭЗ-ВШЭ до 1998 г. не определялся правовой статус партнеров, тогда как с 1998 г. категория супругов включала как зарегистрированные, так и незарегистрированные браки.

${ }^{5}$ К детям относятся родные или усыновленные дети.

6 Также называют нуклеарной или супружеской семьей.
} 
домохозяйств с детьми снизилась на 42\%. Результаты описательного анализа отражают основные демографические тренды в России - отсрочка вступления в брак и рождения первого ребенка, малодетность [Захаров 2006]. Увеличение среднего возраста материнства и рост бездетных домохозяйств связаны с ростом одиночных домохозяйств, сокращение рождаемости - со снижением супружеских и неполных семей с детьми.

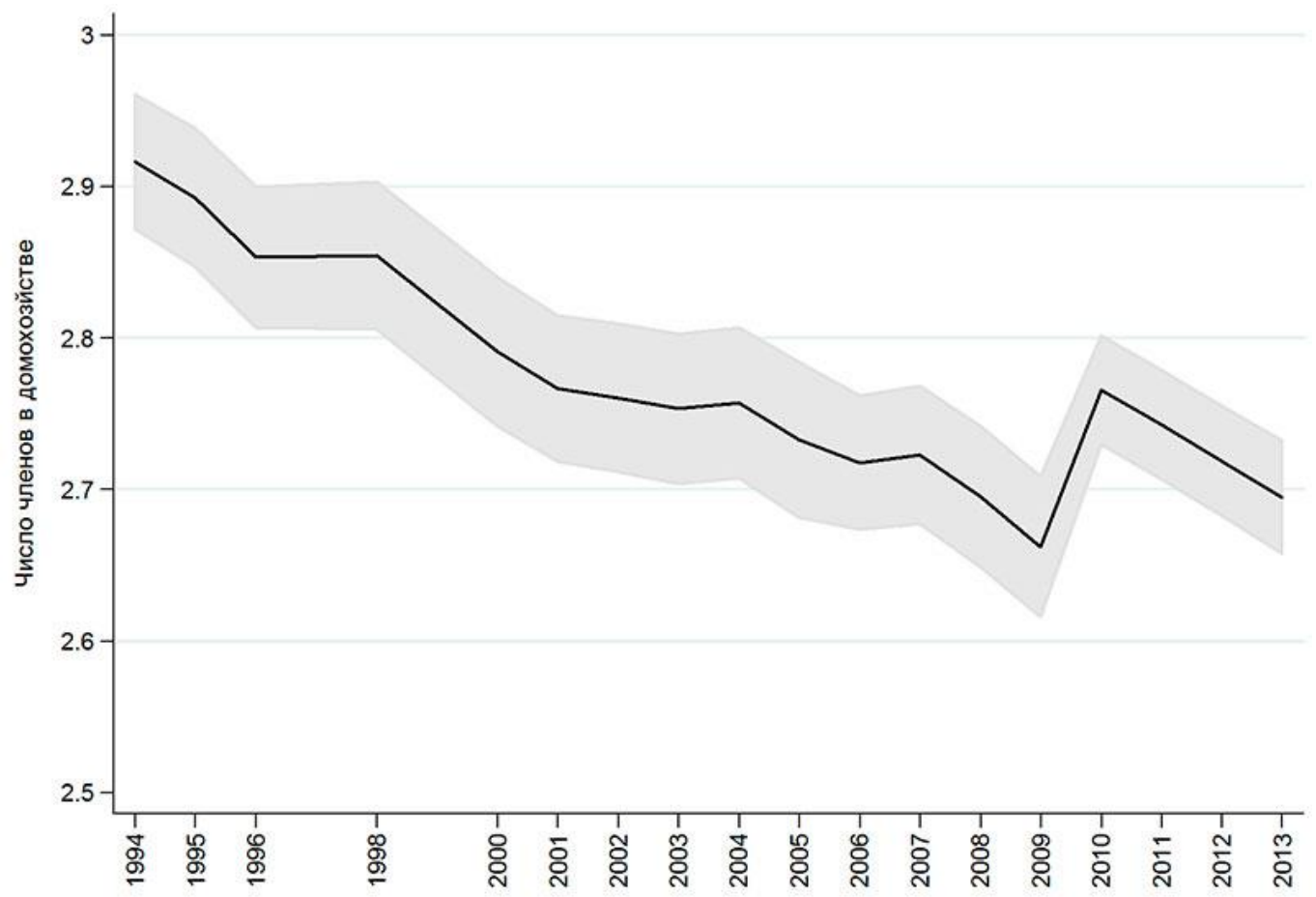

Рисунок 1. Изменение среднего размера домохозяйства, РМЭЗ за 1994-2013

В таблице П-2 Приложения приведено распределение переходов между разными типами домохозяйств за 1994-2013 гг. Для каждого домохозяйства переход классифицируется в соответствии с начальным и конечным типом. Пять типов домохозяйств создают матрицу переходов размером 5х5. Диагональные клетки представляют случаи, когда не было перемещений. Наиболее стабильными оказались одиночные домохозяйства - более $90 \%$ всех переходов этих домохозяйств осуществлялось без смены статуса. Наименее стабильными оказались неполные домохозяйства с детьми. Подавляющая часть неполных домохозяйств, сменивших статус в течение рассматриваемого периода, более вероятно будет объединяться в расширенные семьи. Расширенные домохозяйства в качестве конечного типа характерны и для супружеских домохозяйств с детьми. 


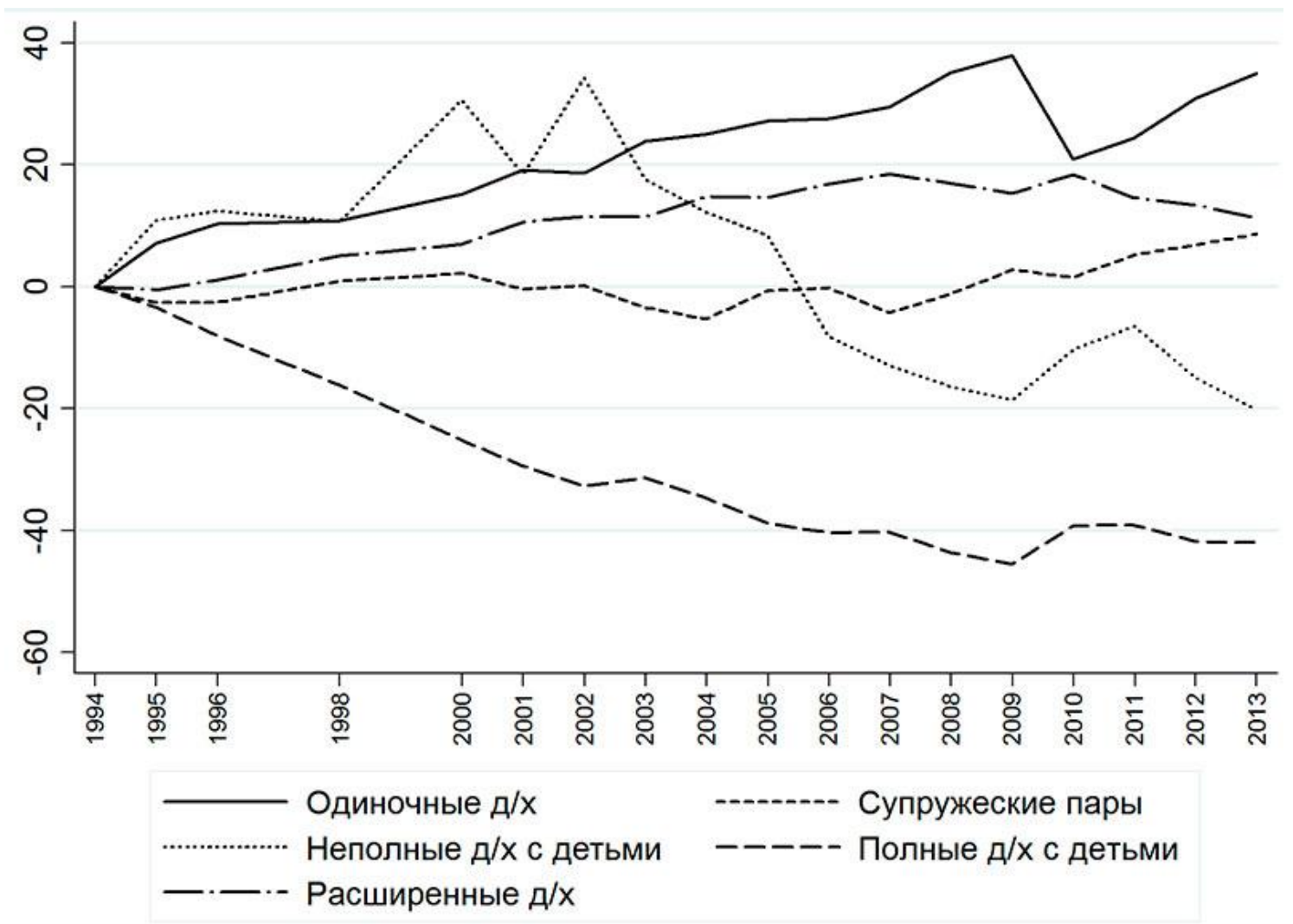

Рисунок 2. Динамика домохозяйств по типам, РМЭЗ за 1994-2013

В таблице П-3 Приложения приведено распределение домохозяйств по основным характеристикам, которые мы будем использовать в анализе. Около $80 \%$ одиночных домохозяйств и более 90\% неполных семей являются «женскими», более $70 \%$ одиночных домохозяйств и супружеских пар имеют во главе члена домохозяйства старше 50 лет, тогда как подавляющее большинство всех домохозяйств с детьми (полных и неполных) имеют главу домохозяйства средней возрастной категории от 30 до 50 лет. Более половины всех опрашиваемых домохозяйств в выборке проживают в городах, отличных от Москвы и СанктПетербурга, в Уральском и Северо-Западном округах.

\section{МЕТодологИя}

Изменения структуры домохозяйства мы исследовали, используя анализ дожития (survival analysis). Пусть $T$ - это время ожидания до изменения структуры домохозяйства (время дожития), тогда функция дожития представлена как вероятность того, что структура домохозяйства не изменилась к моменту времени $t$ :

$$
S(t)=P(T>t) \text {, где } S(t)=1 \text { для } t=0 \text { и } S(t)=0 \text { для } t=\infty .
$$

Мы оцениваем функцию дожития с помощью метода Каплана-Мейера, где вероятность дожития определяется как отношение числа домохозяйств, сохранивших свою структуру к моменту времени $t$, к общему числу домохозяйств, которые наблюдались до этого момента и были подвержены риску изменения структуры. Общая вероятность дожития до момента времени $t$ рассчитывается путем перемножения всех вероятностей, предшествующих этому 
времени. Поскольку временные интервалы определяются периодичностью обследования РМЭЗ, мы измеряем длительность пребывания в группе риска с 1994 по 2013 г. с интервалом в один год. Недостатком использования метода Каплана-Мейера для оценки интенсивности демографических переходов является невозможность исключения влияния возрастной структуры населения. Модель пропорциональных рисков позволяет проанализировать влияние различных факторов на риск дожития домохозяйства:

$$
h_{i j}(t)=\exp \left[\alpha_{i j}(t)+\beta_{i j} X+\gamma_{i j} Z(t)\right],
$$

где $i, j=1, \ldots 5$ - индексы для каждого типа домохозяйства; $h_{i j}(t)$ - риск перехода домохозяйства из типа $i$ в тип $j$ к моменту времени $t ; X$ - набор объясняющих переменных, постоянных во времени; $Z(t)$ - набор объясняющих переменных, значение которых может меняться (функция от времени $t) ; \alpha_{i j}, \beta_{i j}, \gamma_{i j}$ - оцениваемые параметры ${ }^{7}$. Влияние объясняющих переменных одинаково для всех моментов времени $t^{8}$.

Для каждого из пяти типов домохозяйств движение в один из оставшихся четырех типов рассматривается как набор взаимозависимых конкурирующих рисков. Таким образом, изменение структуры домохозяйства в одном направлении исключает либо существенно меняет вероятность изменения структуры в других направлениях [Fine, Gray 1999]. Риск является функцией от времени дожития $t$, которая полностью не определена. Для тех домохозяйств, у которых произошло изменение структуры, время $t$ представляет собой время до этого события. Для тех домохозяйств, у которых изменение структуры не произошло, время $t$ представляет собой время до выбытия из обследования.

Мы учитываем только те изменения в структуре домохозяйств, которые произошли после 1994 г., и анализируем только те переходы, которые были сделаны домохозяйствами в 1994-2013 гг. Таким образом, время дожития становится определенным только для тех домохозяйств, у которых произошло это изменение. Все незавершенные переходы, сделанные домохозяйствами в 1994-2013 гг., включаются в оцениваемую процедуру как цензурированные справа наблюдения. Кроме того, домохозяйства могут выбывать из обследования в силу разных обстоятельств (например, смена места жительства), включаться в обследование в середине или конце периода наблюдения. Это особенно важно в случае использования данных РМЭЗ, поскольку существует значительное истощение панели: лишь около 17\% домохозяйств из тех, которые были опрошены в 1994 г., остались в панели до 2013 г. и участвовали во всех волнах обследования. Модели дожития позволяют преодолеть проблему смещенности оценки, которая может возникнуть как вследствие неравномерности включения домохозяйств в обследование, так и вследствие выбытия домохозяйств. При допущении, что причины выбытия или неравномерного включения домохозяйств в обследование не связаны с последующим риском изменения структуры (независимое

\footnotetext{
7 В анализе мы будем использовать экспоненциальное распределение, параметры которого оцениваются с помощью метода максимального правдоподобия.

${ }^{8}$ Мы также оценивали модель пропорциональных рисков, при которой влияние объясняющих переменных из набора $Z$ может меняться во времени. Мы обнаружили, что модель добавляет небольшую дополнительную объясняющую силу.
} 
цензурирование), данный метод анализа дает несмещенную оценку риска всех изменений в структуре, которые произошли после 1994 г.

В соответствие с результатами предыдущих исследований мы выделяем следующие переменные, которые могут влиять на риск дожития домохозяйства: демографические факторы (возраст и пол главы домохозяйства ${ }^{9}$ ), экономические факторы (уровень благосостояния домохозяйства) и региональные факторы (тип поселения, проживание в мегаполисе, регион проживания) ${ }^{10}$. Поскольку разные типы домохозяйств могут представлять различные фазы цикла развития одного и того же домохозяйства, структура которого меняется по мере старения и взросления его членов, мы включаем возраст главы домохозяйства в качестве контрольной переменной. Демографические и региональные факторы, фиксированные во времени, измеряются на момент перехода домохозяйства из одного типа в другой $(X)$. Уровень благосостояния домохозяйства мы измеряем на момент времени, предшествующий переходу домохозяйства из одного типа в другой (Z). Например, уровень благосостояния в 2000 г. используется для того, чтобы предсказать риск перехода домохозяйства в 2001-2002 гг. Общие расходы ${ }^{11}$ домохозяйства используются как мера благосостояния. Мы предполагаем, что молодой возраст и женский пол главы домохозяйства, а также проживание в городе/мегаполисе будут способствовать нестабильности структуры домохозяйства. Мы также ожидаем увидеть рост степени риска для домохозяйств с низким уровнем благосостояния.

\section{РезУЛьтаты}

На рисунке 3 представлены оценки функции дожития Каплана-Мейера и зависимость стабильности структуры от времени. Функция дожития представлена невозрастающей ступенчатой функцией со скачками в тех моментах, в которых происходит изменение структуры одного или нескольких домохозяйств. Результаты показывают, что проживание в неполных домохозяйствах с детьми является кратковременным - 25\% домохозяйств меняют свою структуру после одного года, после четырех лет эта доля возрастает до 50\%. Медианное время дожития ${ }^{12}$ для одиночных домохозяйств и супружеских пар без детей составляет восемь лет, для расширенных семей - семь лет. Также существует $25 \%$-ная вероятность, что супружеские пары и расширенные домохозяйства останутся стабильными в течение 19 лет (максимальный наблюдаемый период в нашей выборке). Наиболее стабильными оказались полные домохозяйства с детьми - вероятность изменения их структуры через год составляет $10 \%$, три четверти домохозяйств сохраняют свою структуру в течение шести лет, более половины домохозяйств в выборке не меняют свою структуру за ведь период обследования.

\footnotetext{
${ }^{9}$ Под главой домохозяйства мы понимаем члена домохозяйства с максимальным индивидуальным доходом. В случае, когда доходы членов домохозяйства равны, главой становится референтный член домохозяйства.

${ }^{10}$ Мы также включали в анализ степень участия домохозяйства на рынке труда (долю занятых на рынке труда членов домохозяйства) как меру самодостаточности домохозяйства, но позже убрали эту переменную из-за мультиколлинеарности с расходами.

11 Общие расходы домохозяйства были дефлированы на основе региональных индексов роста потребительских цен декабря к декабрю предыдущего года (данные Росстата) и, таким образом, выражены в ценах 2009 г.

12 Время, к которому половина всех домохозяйств изменяет свою структуру.
} 


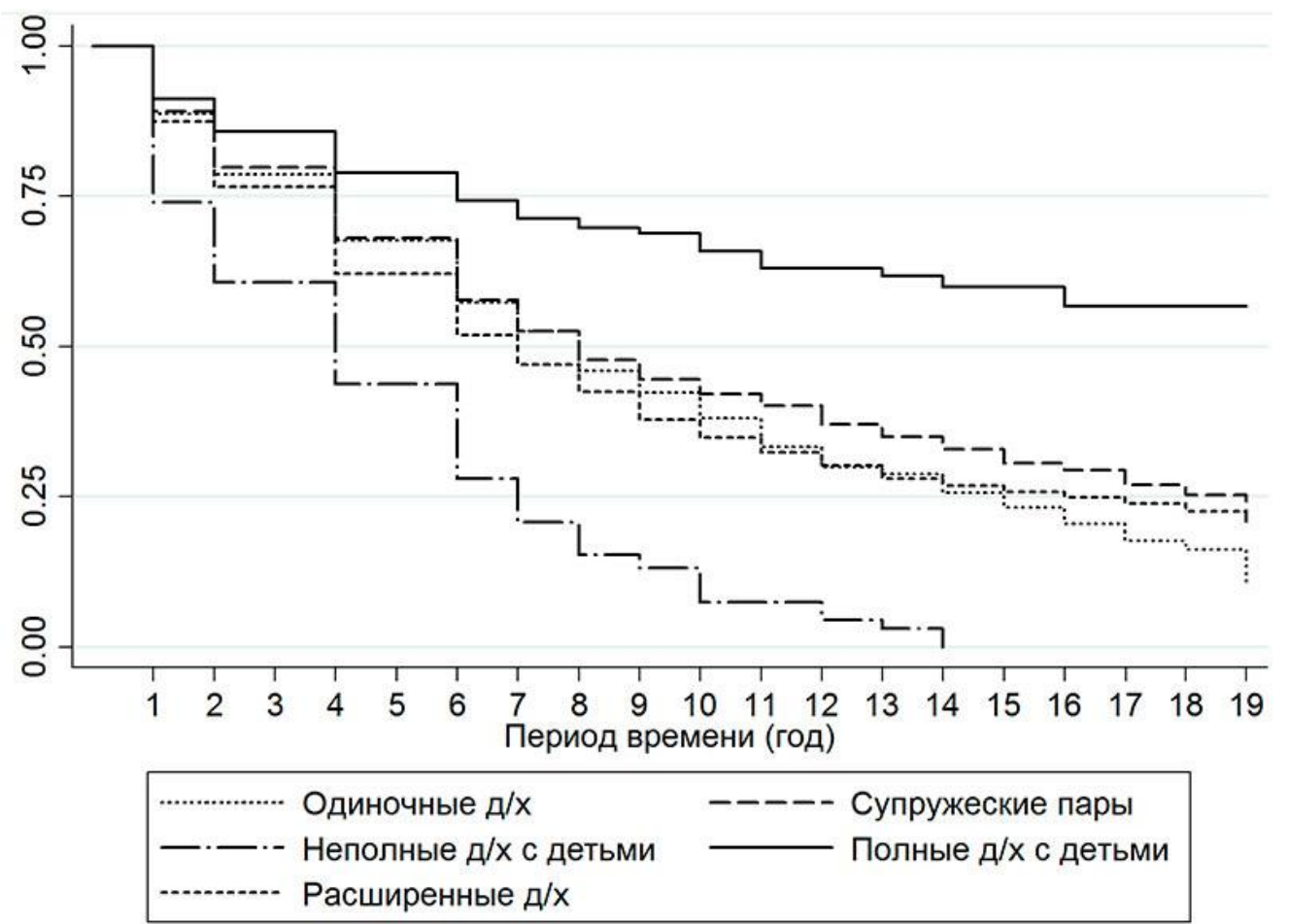

Рисунок 3. Функция дожития Каплана-Мейера, РМЭЗ за 1994-2013

Результаты оценки уравнения (2) представлены в таблицах П-4 - П-8 Приложения. Таблицы сгруппированы по начальному типу домохозяйства. Относительный риск, связанный с объясняющими характеристиками, представлен в экспоненциальной форме $\exp \left(\hat{\beta}_{i j}\right)$, где $\hat{\beta}_{i j}$ - оценка коэффициента переменной из наборов $\mathrm{X}$ или $\mathrm{Z}$ при переходе домохозяйства из типа $i$ в тип $j$. Базовая функция риска для референтной группы выводится из уравнения (2) как $\exp \left(\hat{\alpha}_{i j}(t)\right)$. В нашем случае референтной группой выступает домохозяйство, главой которого является мужчина в возрасте 30-49 лет, проживающее в городе Центрального федерального округа, отличном от Москвы и Санкт-Петербурга, на момент начала своих перемещений. В то время как числовая интерпретация полученных оценок для модели с конкурирующими рисками затруднительна, можно говорить о направлении и значимости связи между объясняющими переменными и риском. Если относительный риск равен единице, это говорит об отсутствии связи, в случае, если он больше единицы, - рост объясняющих переменных связан с ростом риска, если меньше единицы - рост переменных ведет к снижению риска ${ }^{13}$.

Одиночные домохозяйства. Результаты оценки уравнения (2) представлены в таблице П-4 Приложения. При прочих равных условиях вероятность перехода для одиноких женщин в неполные и расширенные домохозяйства гораздо выше, чем для одиноких мужчин. Возрастная группа по-разному влияет на нестабильность одиночных домохозяйств. Для индивидов в возрасте до 29 лет вероятность объединения в супружеские пары и домохозяйства с детьми выше, а вероятность объединения в расширенные домохозяйства ниже, чем для индивидов в возрасте от 30 до 50 лет. Для одиноких индивидов старше 50 лет вероятность объединения в расширенные домохозяйства увеличивается, а вероятность образования

\footnotetext{
${ }^{13}$ Мы рассматриваем влияние объясняющих переменных как значимое, если $p$-value $<0,05$.
} 
супружеских домохозяйств с детьми снижается по сравнению с одинокими индивидами от 30 до 50 лет. Проживание в сельской местности снижает вероятность объединения одиноких индивидов в расширенные домохозяйства, в то время как проживание в Москве/СанктПетербурге, наоборот, ее повышает. Рост благосостояния одиноких индивидов приводит к снижению вероятности переходов в любом направлении.

Супружеские napbl. Результаты оценки уравнения (2) представлены в таблице П-5 Приложения. Для супружеских пар, главой которых является женщина, вероятность перехода в одиночные домохозяйства, супружеские домохозяйства с детьми и расширенные домохозяйства ниже, чем для пар с мужчиной во главе. Молодой возраст главы супружеской пары увеличивает вероятность появления детей и снижает вероятность перехода в расширенные домохозяйства по сравнению с референтной возрастной группой. Для супружеских пар с главой в возрасте от 50 лет и старше повышается риск перехода в одиночные и расширенные домохозяйства, но снижается вероятность появления детей. Проживание в сельской местности и мегаполисах снижает вероятность появления детей по сравнению с проживанием в городе. Обеспеченные супружеские пары менее вероятно будут расходиться и более вероятно - объединяться в расширенные домохозяйства.

Неполные домохозяйства с детьми. Результаты оценки уравнения (2) представлены в таблице П-6 Приложения. Для одиноких женщин с детьми риск перехода в любом направлении выше, чем для одиноких мужчин с детьми. Для молодых одиноких родителей в возрастной категории до 30 лет вероятность создания полного домохозяйства выше, а вероятность объединения в расширенные домохозяйства ниже по сравнению с одинокими родителями в возрасте от 30 до 50 лет. Для пожилых одиноких родителей значительно снижается риск перехода в любом направлении по сравнению с референтной возрастной группой. Проживание в сельской местности снижает вероятность объединения в полные и расширенные домохозяйства по сравнению с проживанием в городе. Рост уровня благосостояния значимо снижает вероятность объединения в расширенные домохозяйства.

Полные домохозяйства с детьми. Результаты оценки уравнения (2) представлены в таблице П-7 Приложения. Если главой супружеского домохозяйства с детьми является женщина, то повышается риск образования неполной семьи и снижается вероятность объединения в расширенные домохозяйства. Молодой возраст главы домохозяйства увеличивает риск образования неполной семьи и снижает риск перехода в расширенные домохозяйства по сравнению с домохозяйствами, главы которых имеют возраст от 30 до 50 лет. Проживание в сельской местности увеличивает вероятность перехода в супружеские пары и расширенные домохозяйства по сравнению с проживанием в городе. Рост уровня благосостояния повышает вероятность объединения супружеской семьи с детьми в расширенные домохозяйства.

Расширенные домохозяйства. Результаты оценки уравнения (2) представлены в таблице П-7 Приложения. Женский пол главы домохозяйства повышает вероятность перехода в категорию одиночных и неполных домохозяйств и снижает вероятность перехода в супружеские бездетные домохозяйства и домохозяйства с детьми. У домохозяйств, глава 
которых младше 30 или старше 50 лет, возрастает риск перехода в одиночные домохозяйства и вероятность образования супружеской пары по сравнению с референтным домохозяйством. В старших возрастах также существенно ниже вероятность перехода в полные и неполные домохозяйства с детьми. Проживание в сельской местности снижает риск перехода в одиночные домохозяйства по сравнению с проживанием в городе. Рост уровня благосостояния домохозяйства снижает вероятность одиночного проживания и повышает вероятность перехода в супружеские домохозяйства.

Таким образом, большинство переходов, сделанных российскими домохозяйствами в 1994-2013 гг., согласуются со стадиями жизненного цикла, в процессе которого индивиды, входящие в состав домохозяйства, по мере взросления проходят разные этапы формирования и распада домохозяйства.

\section{ЗАКЛЮЧЕНИЕ}

Мы использовали панельные данные РМЭЗ для того, чтобы изучить перемещения индивидов между разными типами домохозяйств, предполагая, что в каждый конкретный момент времени домохозяйство сталкивается с вероятностью перехода в любой из следующих типов: одиночные домохозяйства, супружеские пары без детей, неполные домохозяйства с детьми, супружеские домохозяйства с детьми, расширенные домохозяйства. Была использована простая модель дожития, в которой вероятные направления изменения домохозяйства рассматривались как набор конкурирующих рисков. Наши результаты подтверждают факты других исследований по кросс-секционным данным, а также добавляют новые сведения на базе панельного анализа.

Мы начали с описательного анализа изменения структуры домохозяйств. Несмотря на то, что подавляющее большинство домохозяйств были стабильными с точки зрения структуры, почти все домохозяйства, сменившие тип, чаще всего переходили в расширенные домохозяйства. Далее относительная стабильность пяти типов домохозяйств была оценена с помощью кривых дожития. Полные домохозяйства с детьми оставались наиболее стабильными: более половины домохозяйств в выборке не меняли свою структуру за весь период обследования. Нахождение в неполных домохозяйствах с детьми, наоборот, оказалось кратковременным: 50\% домохозяйств поменяли структуру после четырех лет. Медианное время дожития для остальных типов домохозяйств составило 7-8 лет.

Затем мы оценили модель пропорционального риска для каждого типа домохозяйства, контролируя демографические, экономические и региональные характеристики. Молодой возраст главы домохозяйства вне зависимости от начального типа повышает вероятность заключения брака и появления детей, что согласуется с жизненным циклом домохозяйства. Наши результаты также показали, что практически для всех начальных типов женский пол главы домохозяйства связан с повышенным риском образования неполной семьи, а проживание в сельской местности, Москве или Санкт-Петербурге связано с более низкой по сравнению с проживанием в других городах вероятностью заключения брака и появления детей. Мы также обнаружили, что бездетные домохозяйства, главы которых старше 50 лет, подвержены высокому риску объединения в расширенные домохозяйства. Это говорит о 
важности расширенных семей для данной категории. В то же время рост благосостояния домохозяйств с детьми значимо увеличивает риск объединения в расширенные домохозяйства, отражая способность этих типов домохозяйств принимать в свой состав родственников и не родственников. Причинами описанных выше процессов могут служить неразвитость системы социального обслуживания, перекладывающая обслуживание престарелых родственников на плечи семьи, а также неразвитость института детских садов, вынуждающая семьи, в которых оба родителя работают, привлекать своих пожилых родственников для ухода за детьми.

\section{БЛАГОДАРНОСТИ}

Мы признательны анонимным рецензентам за ценные предложения, которые существенно помогли улучшить первоначальную версию статьи; особенно благодарим за содержательный комментарий относительно демографического поведения семьи и домохозяйства.

\section{ЛИТЕРАТУРА}

Волков А. Г. (1986). Семья - объект демографии. М: Мысль.

Головляницина Е. Б. (2007). Роль социально-психологических факторов в репродуктивных намерениях // Родители и дети, мужчины и женщины в семьи и обществе / Под ред. Т.М. Малевой, О.В. Синявской. НИСП: 217-250.

Захаров С.В. (2006). Возраст вступления в первый брак // Демографическая модернизация России, 1900-2000 / Под ред. А.Г. Вишневского. М: Новое издательство.

Захаров С.В. (2007). Трансформация брачно-партнерских отношений в России: «золотой век» традиционного брака близится к закату? // Родители и дети, мужчины и женщины в семьи и обществе / Под ред. Т.М. Малевой, О.В. Синявской. НИСП: 75-126.

Малева Т.М., О.В. Синявская (2007). Социально-экономические факторы рождаемости в России: эмпирические измерения и вызовы социальной политики // Родители и дети, мужчины и женщины в семье и обществе/ Под ред. Т.М. Малевой, О.В. Синявской. НИСП: 171-216.

Прокофьева Л.М. (2007). Домохозяйство и семья: особенности структуры населения в России // Родители и дети, мужчины и женщины в семье и обществе / Под ред. Т.М. Малевой, О.В. Синявской. НИСП: 251-266.

Рощина Я.М., А.В. Бойков (2005). Факторы фертильности в современной России // Российский консорциум экономических исследований и образования. Серия «Научные доклады». WP № 05/04

Синявская О.В., С.В. Захаров, М.А. Карцева (2007). Поведение женщины на рынке труда и деторождение в современной России // Родители и дети, мужчины и женщины в семье и обществе / Под ред. Т.М. Малевой, О.В. Синявской. НИСП: 421-476.

Синявская О.В., А.О. Тындик (2009). Рождаемость в современной России: от планов к действиям? // SPERO. № 5: 131-158. 
Abanokova K., M. Lokshin (2015). Changes in household composition as a shock-mitigating strategy // Economics of Transition. 23(2): 371-388.

Fine J., R. Gray (1999). A proportional hazards model for the subdistribution of a competing risk. Journal of the American Statistical Association. 94: 496-509.

Slonimczyk F., A.V. Yurko (2014). Assessing the impact of the maternity capital policy in Russia // Labour Economics. 30: 265-281. 


\section{ПРИЛОЖЕНИЕ}

Таблица П-1. Распределение домохозяйств по данным РМЭЗ-ВШЭ и переписей и микропереписи населения в зависимости от размера, \%

\begin{tabular}{|c|c|c|c|c|c|c|c|c|c|}
\hline \multirow[b]{2}{*}{ Состав и размер домохозяйства } & \multicolumn{3}{|c|}{1994} & \multicolumn{3}{|c|}{2002} & \multicolumn{3}{|c|}{2010} \\
\hline & $\begin{array}{l}\rho \\
\sum_{a}^{n} \\
\sum^{n}\end{array}$ & 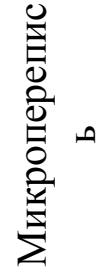 & 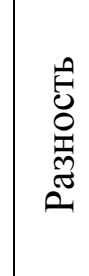 & 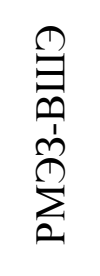 & 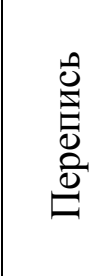 & 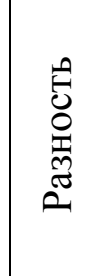 & $\frac{\cap}{\bigcap_{0}^{n}}$ & 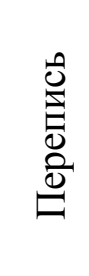 & 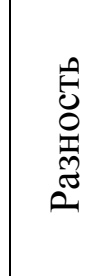 \\
\hline \multicolumn{10}{|l|}{ Домохозяйства, состоящие из: } \\
\hline одного человека & 16,8 & 16,2 & 0,6 & 19,7 & 22,3 & $2,6^{*}$ & 19,9 & 25,7 & $-5,8^{*}$ \\
\hline двух человек & 26,8 & 23,4 & $3,4 *$ & 30,2 & 27,6 & $2,6^{*}$ & 29,4 & 28,5 & 0,9 \\
\hline трех человек & 24,0 & 21,8 & $2,2 *$ & 22,9 & 23,8 & 0,9 & 23,5 & 22,5 & 1,0 \\
\hline четырех человек & 21,2 & 24,4 & $3,2 *$ & 16,7 & 17,0 & 0,3 & 16,7 & 14,5 & $2,2 *$ \\
\hline пяти человек & 7,2 & 9,6 & $2,4 *$ & 6,2 & 5,7 & 0,5 & 6,1 & 5,3 & 0,8 \\
\hline шести и более человек & 4,0 & 4,6 & 0,6 & 4,4 & 3,6 & 0,8 & 4,5 & 3,4 & $1,1^{*}$ \\
\hline Средний размер домохозяйства & 2,9 & $3,4^{\mathrm{a}}$ & & 2,8 & 2,7 & & 2,8 & 2,6 & \\
\hline
\end{tabular}

Таблица П-2. Распределение переходов по типам домохозяйств за 1994-2013 гг. (как доля от начальных домохозяйств), РМЭЗ-ВШЭ

\begin{tabular}{|c|c|c|c|c|c|c|}
\hline \multirow[b]{2}{*}{ Начальный тип домохозяйства } & \multicolumn{5}{|c|}{ Конечный тип домохозяйства } & \multirow[b]{2}{*}{ Число переходов } \\
\hline & 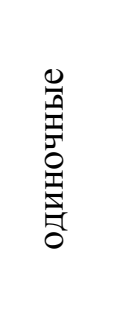 & 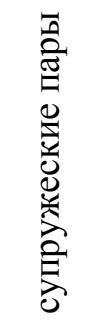 & 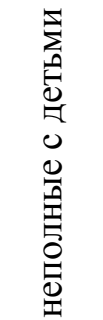 & 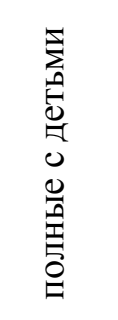 & 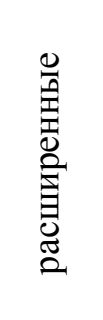 & \\
\hline Одиночные & 0,917 & 0,023 & 0,002 & 0,005 & 0,054 & 12714 \\
\hline Супружеские пары & 0,041 & 0,872 & 0,001 & 0,029 & 0,057 & 12681 \\
\hline Неполные с детьми & 0,017 & 0,000 & 0,744 & 0,091 & 0,147 & 2653 \\
\hline Полные с детьми & 0,003 & 0,008 & 0,021 & 0,860 & 0,108 & 14767 \\
\hline Расширенные & 0,033 & 0,046 & 0,006 & 0,026 & 0,889 & 27491 \\
\hline
\end{tabular}


Таблица П-3. Описательная статистика переменных по типам домохозяйств, РМЭЗ-ВШЭ, 1994-2013

\begin{tabular}{|c|c|c|c|c|c|c|c|c|c|c|}
\hline \multirow[b]{2}{*}{ Характеристики домохозяйств } & \multicolumn{2}{|c|}{ Одиночные } & \multicolumn{2}{|c|}{ Супружеские пары } & \multicolumn{2}{|c|}{ Неполные с детьми } & \multicolumn{2}{|c|}{ Полные с детьми } & \multicolumn{2}{|c|}{ Расширенные } \\
\hline & Средняя & $\begin{array}{c}\text { Стандартная } \\
\text { ошибка }\end{array}$ & Средняя & $\begin{array}{c}\text { Стандартная } \\
\text { ошибка }\end{array}$ & Средняя & $\begin{array}{c}\text { Стандартная } \\
\text { ошибка }\end{array}$ & Средняя & $\begin{array}{c}\text { Стандартная } \\
\text { ошибка }\end{array}$ & Средняя & $\begin{array}{c}\text { Стандартная } \\
\text { ошибка }\end{array}$ \\
\hline $\begin{array}{l}\text { Женский пол главы } \\
\text { домохозяйства }\end{array}$ & 0,784 & 0,412 & 0,382 & 0,486 & 0,947 & 0,224 & 0,332 & 0,471 & 0,520 & 0,500 \\
\hline \multicolumn{11}{|l|}{ Возраст главы домохозяйства } \\
\hline до 29 лет & 0,088 & 0,284 & 0,119 & 0,324 & 0,185 & 0,388 & 0,272 & 0,445 & 0,183 & 0,387 \\
\hline от 30 до 49 лет & 0,122 & 0,327 & 0,176 & 0,381 & 0,759 & 0,428 & 0,698 & 0,459 & 0,411 & 0,492 \\
\hline от 50 лет и старше & 0,790 & 0,407 & 0,705 & 0,456 & 0,056 & 0,229 & 0,031 & 0,172 & 0,406 & 0,491 \\
\hline $\begin{array}{l}\text { Проживание в Москве/Санкт- } \\
\text { Петербурге }\end{array}$ & 0,127 & 0,333 & 0,078 & 0,268 & 0,096 & 0,295 & 0,081 & 0,273 & 0,144 & 0,351 \\
\hline Проживание в других городах & 0,590 & 0,492 & 0,594 & 0,491 & 0,643 & 0,479 & 0,614 & 0,487 & 0,545 & 0,498 \\
\hline Проживание в селе & 0,284 & 0,451 & 0,329 & 0,470 & 0,261 & 0,439 & 0,305 & 0,460 & 0,312 & 0,463 \\
\hline \multicolumn{11}{|l|}{ Федеральный округ } \\
\hline Центральный & 0,127 & 0,333 & 0,078 & 0,268 & 0,096 & 0,295 & 0,081 & 0,273 & 0,144 & 0,351 \\
\hline Северо-Западный & 0,217 & 0,412 & 0,214 & 0,410 & 0,169 & 0,375 & 0,179 & 0,383 & 0,178 & 0,382 \\
\hline Южный & 0,062 & 0,241 & 0,072 & 0,258 & 0,125 & 0,331 & 0,086 & 0,280 & 0,062 & 0,241 \\
\hline Приволжский & 0,111 & 0,314 & 0,117 & 0,321 & 0,126 & 0,332 & 0,140 & 0,347 & 0,172 & 0,378 \\
\hline Уральский & 0,228 & 0,419 & 0,231 & 0,421 & 0,219 & 0,414 & 0,240 & 0,427 & 0,207 & 0,405 \\
\hline Сибирский & 0,095 & 0,294 & 0,095 & 0,293 & 0,093 & 0,290 & 0,094 & 0,292 & 0,080 & 0,271 \\
\hline Дальневосточный & 0,124 & 0,329 & 0,147 & 0,354 & 0,134 & 0,341 & 0,130 & 0,337 & 0,108 & 0,311 \\
\hline $\begin{array}{l}\text { Логарифм расходов } \\
\text { домохозяйства }^{14}\end{array}$ & 8,565 & 0,989 & 9,239 & 0,874 & 9,250 & 0,871 & 9,696 & 0,872 & 9,644 & 0,884 \\
\hline
\end{tabular}

14 Расходы дефлированы 2009 г. 


\section{Таблица П-4. Оценки модели пропорциональных рисков для одиночных домохозяйств, РМЭЗ-ВШЭ, 1994-2013}

\begin{tabular}{|c|c|c|c|c|c|c|c|c|}
\hline \multirow{3}{*}{$\begin{array}{l}\text { Начальный тип } \\
\text { домохозяйства и его } \\
\text { характеристики }\end{array}$} & \multicolumn{8}{|c|}{ Конечный тип домохозяйства } \\
\hline & \multicolumn{2}{|c|}{ супружеские пары } & \multicolumn{2}{|c|}{ неполные с детьми } & \multicolumn{2}{|c|}{ супружеские с детьми } & \multicolumn{2}{|c|}{ расширенные } \\
\hline & $\begin{array}{c}\text { Отношение } \\
\text { рисков }\end{array}$ & $\begin{array}{c}\text { Стандартная } \\
\text { ошибка }\end{array}$ & $\begin{array}{c}\text { Отношение } \\
\text { рисков }\end{array}$ & $\begin{array}{c}\text { Стандартная } \\
\text { ошибка }\end{array}$ & $\begin{array}{c}\text { Отношение } \\
\text { рисков }\end{array}$ & $\begin{array}{c}\text { Стандартная } \\
\text { ошибка }\end{array}$ & $\begin{array}{c}\text { Отношение } \\
\text { рисков }\end{array}$ & $\begin{array}{c}\text { Стандартная } \\
\text { ошибка } \\
\end{array}$ \\
\hline $\begin{array}{l}\text { Женский пол главы } \\
\text { домохозяйства }\end{array}$ & $1,333^{*}$ & 0,199 & $6,245 * * *$ & 4,151 & 0,740 & 0,228 & $3,024 * * *$ & 0,338 \\
\hline $\begin{array}{l}\text { Возраст главы } \\
\text { домохозяйства }\end{array}$ & \multicolumn{8}{|c|}{ референтная группа - от 30 до 49 лет } \\
\hline до 29 лет & $2,237 * * *$ & 0,398 & 1,391 & 0,694 & $1,964 * *$ & 0,570 & $0,560 * *$ & 0,133 \\
\hline от 50 лет и старше & 1,106 & 0,195 & - & - & $0,062 * * *$ & 0,045 & $2,683 * * *$ & 0,304 \\
\hline Москва/Санкт-Петербург & $0,560^{*}$ & 0,179 & 0,586 & 0,677 & 1,011 & 0,566 & $1,422 * *$ & 0,215 \\
\hline Тип населенного пункта & \multicolumn{8}{|c|}{ референтная группа - город } \\
\hline Село & $0,746^{*}$ & 0,117 & $0,306^{*}$ & 0,197 & 1,080 & 0,351 & $0,740 * * *$ & 0,075 \\
\hline Федеральныий округ & \multicolumn{8}{|c|}{ референтная группа - Центральный федеральный округ } \\
\hline Северо-западный & $1,949 * * *$ & 0,472 & 1,804 & 1,645 & 1,480 & 0,764 & 1,160 & 0,222 \\
\hline Южный & 0,762 & 0,205 & - & - & 0,660 & 0,397 & 1,137 & 0,171 \\
\hline Приволжский & 0,861 & 0,186 & 1,149 & 0,863 & 1,219 & 0,496 & $0,789 *$ & 0,107 \\
\hline Уральский & 0,965 & 0,267 & 1,391 & 1,303 & 1,021 & 0,560 & 1,040 & 0,178 \\
\hline Сибирский & $1,793 * * *$ & 0,377 & 1,262 & 1,056 & 0,996 & 0,486 & 1,152 & 0,169 \\
\hline Дальневосточный & 0,553 & 0,260 & 3,590 & 3,535 & 0,369 & 0,387 & 1,202 & 0,278 \\
\hline Время начала перехода & $1,035 * * *$ & 0,012 & 1,044 & 0,051 & $1,062 * *$ & 0,027 & 1,007 & 0,009 \\
\hline $\begin{array}{l}\text { Лог общих расходов } \\
\text { домохозяйства }\end{array}$ & $0,955 * * *$ & 0,006 & $0,898 * * *$ & 0,028 & $0,944 * * *$ & 0,020 & $0,948 * * *$ & 0,004 \\
\hline Pseudo Log L & \multicolumn{2}{|c|}{$-1872,76$} & \multicolumn{2}{|c|}{$-131,28$} & \multicolumn{2}{|c|}{$-444,20$} & \multicolumn{2}{|c|}{$-4464,11$} \\
\hline
\end{tabular}


Таблица П-5. Оценки модели пропорциональных рисков для супружеских пар, РМЭЗ-ВШЭ, 1994-2013

\begin{tabular}{|c|c|c|c|c|c|c|c|c|}
\hline \multirow{3}{*}{$\begin{array}{l}\text { Начальный тип } \\
\text { домохозяйства и его } \\
\text { характеристики }\end{array}$} & \multicolumn{8}{|c|}{ Конечный тип домохозяйства } \\
\hline & \multicolumn{2}{|c|}{ одиночные } & \multicolumn{2}{|c|}{ неполные } & \multicolumn{2}{|c|}{ супружеские с детьми } & \multicolumn{2}{|c|}{ расширенные } \\
\hline & $\begin{array}{c}\text { Отношение } \\
\text { рисков }\end{array}$ & $\begin{array}{c}\text { Стандартная } \\
\text { ошибка }\end{array}$ & $\begin{array}{c}\text { Отношение } \\
\text { рисков }\end{array}$ & \begin{tabular}{|c|} 
Стандартная \\
ошибка
\end{tabular} & $\begin{array}{c}\text { Отношение } \\
\text { рисков }\end{array}$ & $\begin{array}{c}\text { Стандартная } \\
\text { ошибка }\end{array}$ & $\begin{array}{c}\text { Отношение } \\
\text { рисков }\end{array}$ & $\begin{array}{c}\text { Стандартная } \\
\text { ошибка }\end{array}$ \\
\hline $\begin{array}{l}\text { Женский пол главы } \\
\text { домохозяйства }\end{array}$ & $0,538 * * *$ & 0,052 & 1,002 & 0,817 & $0,558 * * *$ & 0,082 & $0,519 * * *$ & 0,047 \\
\hline $\begin{array}{l}\text { Возраст главы } \\
\text { домохозяйства }\end{array}$ & \multicolumn{8}{|c|}{ референтная группа - от 30 до 49 лет } \\
\hline до 29 лет & 1,203 & 0,256 & 0,844 & \multirow{2}{*}{0,757} & $6,732 * * *$ & 1,007 & $0,483 * * *$ & 0,084 \\
\hline от 50 лет и старше & $5,490 * * *$ & 0,748 & - & & $0,019 * * *$ & 0,019 & $1,792 * * *$ & 0,174 \\
\hline Москва/Санкт-Петербург & 0,832 & 0,160 & - & - & $0,430 * * *$ & 0,123 & 1,035 & 0,181 \\
\hline Тип населенного пункта & \multicolumn{8}{|c|}{ референтная группа - город } \\
\hline Село & 0,857 & 0,087 & 0,489 & 0,513 & $0,662 * *$ & 0,111 & 0,988 & 0,096 \\
\hline Федеральный округ & \multicolumn{8}{|c|}{ референтная группа - Центральный федеральный округ } \\
\hline Северо-западный & $1,420 *$ & 0,269 & - & - & 0,813 & 0,215 & $1,439 * *$ & 0,254 \\
\hline Южный & 1,052 & 0,170 & - & - & $0,508 * *$ & 0,142 & $1,334 *$ & 0,198 \\
\hline Приволжский & 1,042 & 0,143 & 0,267 & 0,311 & 0,968 & 0,173 & 1,086 & 0,148 \\
\hline Уральский & 0,872 & 0,172 & 0,694 & 0,771 & 0,696 & 0,180 & $1,465^{* *}$ & 0,241 \\
\hline Сибирский & $1,444 * *$ & 0,216 & 0,977 & 0,849 & 0,942 & 0,194 & $1,374 * *$ & 0,208 \\
\hline Дальневосточный & 1,014 & 0,248 & - & - & 0,922 & 0,302 & 1,305 & 0,278 \\
\hline Время начала перехода & 0,995 & 0,010 & 1,014 & 0,038 & $1,045 * * *$ & 0,012 & 0,995 & 0,009 \\
\hline $\begin{array}{l}\text { Лог общих расходов } \\
\text { домохозяйства }\end{array}$ & $0,981 * * *$ & 0,004 & 1,055 & 0,061 & 1,014 & 0,017 & $1,014 * * *$ & 0,005 \\
\hline Pseudo Log L & \multicolumn{2}{|c|}{$-3926,47$} & \multicolumn{2}{|c|}{$-52,50$} & \multicolumn{2}{|c|}{$-1834,74$} & \multicolumn{2}{|c|}{$-4755,73$} \\
\hline
\end{tabular}


Таблица П-6. Оценки модели пропорциональных рисков для неполных домохозяйств с детьми, РМЭЗ-ВШЭ, 1994-2013

\begin{tabular}{|c|c|c|c|c|c|c|}
\hline \multirow{3}{*}{$\begin{array}{l}\text { Начальный тип домохозяйства и его } \\
\text { характеристики }\end{array}$} & \multicolumn{6}{|c|}{ Конечный тип домохозяйства } \\
\hline & \multicolumn{2}{|c|}{ одиночные } & \multicolumn{2}{|c|}{ супружеские с детьми } & \multicolumn{2}{|c|}{ расширенные } \\
\hline & $\begin{array}{l}\text { Отношение } \\
\text { рисков }\end{array}$ & $\begin{array}{l}\text { Стандартная } \\
\text { ошибка }\end{array}$ & $\begin{array}{l}\text { Отношение } \\
\text { рисков }\end{array}$ & $\begin{array}{l}\text { Стандартная } \\
\text { ошибка }\end{array}$ & $\begin{array}{l}\text { Отношение } \\
\text { рисков }\end{array}$ & $\begin{array}{c}\text { Стандартная } \\
\text { ошибка }\end{array}$ \\
\hline Женский пол главы домохозяйства & $6,062 * * *$ & 2,496 & $26,441 * * *$ & 9,015 & $18,132 * * *$ & 4,264 \\
\hline Возраст главы домохозяйства & \multicolumn{6}{|c|}{ референтная группа - от 30 до 49 лет } \\
\hline до 29 лет & $0,440 *$ & 0,204 & $2,140 * * *$ & 0,319 & $0,272 * * *$ & 0,058 \\
\hline от 50 лет и старше & $0,054 * * *$ & 0,034 & $0,019 * * *$ & 0,011 & $0,074 * * *$ & 0,015 \\
\hline Москва/Санкт-Петербург & $0,141 *$ & 0,148 & $0,551 *$ & 0,181 & 1,223 & 0,260 \\
\hline Тип населенного пункта & \multicolumn{6}{|c|}{ референтная группа - город } \\
\hline Село & 0,860 & 0,308 & $0,621 * *$ & 0,109 & $0,757 * *$ & 0,101 \\
\hline Федеральный округ & \multicolumn{6}{|c|}{ референтная группа - Центральный федеральный округ } \\
\hline Северо-западный & 0,368 & 0,283 & 1,166 & 0,335 & $1,867 * * *$ & 0,383 \\
\hline Южный & 0,955 & 0,465 & 1,175 & 0,321 & 1,026 & 0,223 \\
\hline Приволжский & 0,533 & 0,239 & 0,905 & 0,217 & 1,239 & 0,216 \\
\hline Уральский & 1,040 & 0,521 & $1,822 * *$ & 0,464 & 1,342 & 0,291 \\
\hline Сибирский & 0,605 & 0,324 & 1,026 & 0,267 & 1,183 & 0,241 \\
\hline Дальневосточный & 0,639 & 0,502 & 0,796 & 0,349 & 0,871 & 0,283 \\
\hline Время начала перехода & 0,994 & 0,031 & $1,055 * * *$ & 0,015 & $1,022 * *$ & 0,010 \\
\hline Лог общих расходов домохозяйства & 0,989 & 0,013 & 0,984 & 0,013 & $0,963 * * *$ & 0,007 \\
\hline Pseudo Log L & \multicolumn{2}{|c|}{$-345,55$} & \multicolumn{2}{|c|}{$-1379,36$} & \multicolumn{2}{|c|}{$-2533,92$} \\
\hline
\end{tabular}


Таблица П-7. Оценки модели пропорциональных рисков для супружеских домохозяйств с детьми, РМЭЗ-ВШЭ, 1994-2013

\begin{tabular}{|c|c|c|c|c|c|c|c|c|}
\hline \multirow{3}{*}{$\begin{array}{l}\text { Начальный тип } \\
\text { домохозяйства и его } \\
\text { характеристики }\end{array}$} & \multicolumn{8}{|c|}{ Конечный тип домохозяйства } \\
\hline & \multicolumn{2}{|c|}{ одиночные } & \multicolumn{2}{|c|}{ супружеские пары } & \multicolumn{2}{|c|}{ неполные с детьми } & \multicolumn{2}{|c|}{ расширенные } \\
\hline & $\begin{array}{c}\text { Отношение } \\
\text { рисков }\end{array}$ & $\begin{array}{c}\text { Стандартная } \\
\text { ошибка } \\
\end{array}$ & $\begin{array}{c}\text { Отношение } \\
\text { рисков }\end{array}$ & $\begin{array}{c}\text { Стандартная } \\
\text { ошибка } \\
\end{array}$ & $\begin{array}{c}\text { Отношение } \\
\text { рисков }\end{array}$ & $\begin{array}{c}\text { Стандартная } \\
\text { ошибка }\end{array}$ & $\begin{array}{c}\text { Отношение } \\
\text { рисков }\end{array}$ & $\begin{array}{c}\text { Стандартная } \\
\text { ошибка } \\
\end{array}$ \\
\hline $\begin{array}{l}\text { Женский пол главы } \\
\text { домохозяйства }\end{array}$ & 0,733 & 0,226 & 0,842 & 0,163 & $1,462 * * *$ & 0,198 & $0,728 * * *$ & 0,041 \\
\hline $\begin{array}{l}\text { Возраст главы } \\
\text { домохозяйства }\end{array}$ & \multicolumn{8}{|c|}{ референтная группа - от 30 до 49 лет } \\
\hline до 29 лет & 1,540 & 0,474 & $0,199 * * *$ & 0,077 & $1,322 * *$ & 0,187 & $0,312 * * *$ & 0,029 \\
\hline от 50 лет и старше & $0,064 * * *$ & 0,049 & $0,129 * * *$ & 0,040 & $0,035 * * *$ & 0,015 & $0,083 * * *$ & 0,009 \\
\hline Москва/Санкт-Петербург & 0,205 & 0,216 & $0,155 * *$ & 0,114 & 1,207 & 0,343 & 0,967 & 0,105 \\
\hline Тип населенного пункта & \multicolumn{8}{|c|}{ референтная группа - город } \\
\hline Село & 1,719 & 0,579 & $1,573 * *$ & 0,311 & 1,037 & 0,161 & $1,185 * * *$ & 0,074 \\
\hline Федеральный округ & \multicolumn{8}{|c|}{ референтная группа - Центральный федеральный округ } \\
\hline Северо-западный & 1,381 & 0,703 & 0,827 & 0,312 & $2,140 * * *$ & 0,553 & 0,883 & 0,105 \\
\hline Южный & 0,642 & 0,347 & 0,705 & 0,211 & 1,182 & 0,333 & 1,013 & 0,094 \\
\hline Приволжский & 0,917 & 0,375 & 1,163 & 0,304 & $1,495 *$ & 0,340 & 1,069 & 0,088 \\
\hline Уральский & 0,542 & 0,352 & 0,981 & 0,341 & $1,996 * * *$ & 0,525 & 1,118 & 0,118 \\
\hline Сибирский & 0,542 & 0,314 & 0,790 & 0,270 & $1,584^{*}$ & 0,400 & 1,059 & 0,102 \\
\hline Дальневосточный & 0,851 & 0,559 & $0,128 * *$ & 0,133 & 1,367 & 0,482 & $1,366 * * *$ & 0,164 \\
\hline Время начала перехода & 1,011 & 0,030 & 0,983 & 0,019 & 1,007 & 0,012 & $0,966 * * *$ & 0,005 \\
\hline $\begin{array}{l}\text { Лог общих расходов } \\
\text { домохозяйства }\end{array}$ & 0,980 & 0,020 & 1,011 & 0,010 & 0,997 & 0,012 & $1,040 * * *$ & 0,004 \\
\hline Pseudo Log L & \multicolumn{2}{|c|}{$-389,89$} & \multicolumn{2}{|c|}{$-941,91$} & \multicolumn{2}{|c|}{$-1900,88$} & \multicolumn{2}{|c|}{$-10258,15$} \\
\hline
\end{tabular}

Примечания: * - $p<0,1, * *-p<0,05, * * *-p<0,01$ 
Таблица П-8. Оценки модели пропорциональных рисков для расширенных домохозяйств, РМЭЗ-ВШЭ, 1994-2013

\begin{tabular}{|c|c|c|c|c|c|c|c|c|}
\hline \multirow{3}{*}{$\begin{array}{l}\text { Начальный тип } \\
\text { домохозяйства и его } \\
\text { характеристики }\end{array}$} & \multicolumn{8}{|c|}{ Конечный тип домохозяйства } \\
\hline & \multicolumn{2}{|c|}{ одиночные } & \multicolumn{2}{|c|}{ супружеские пары } & \multicolumn{2}{|c|}{ неполные с детьми } & \multicolumn{2}{|c|}{ супружеские с детьми } \\
\hline & $\begin{array}{c}\text { Отношение } \\
\text { рисков }\end{array}$ & $\begin{array}{c}\text { Стандартная } \\
\text { ошибка } \\
\end{array}$ & $\begin{array}{c}\text { Отношение } \\
\text { рисков }\end{array}$ & $\begin{array}{c}\text { Стандартная } \\
\text { ошибка } \\
\end{array}$ & $\begin{array}{c}\text { Отношение } \\
\text { рисков }\end{array}$ & $\begin{array}{c}\text { Стандартная } \\
\text { ошибка } \\
\end{array}$ & $\begin{array}{c}\text { Отношение } \\
\text { рисков }\end{array}$ & $\begin{array}{c}\text { Стандартная } \\
\text { ошибка } \\
\end{array}$ \\
\hline $\begin{array}{l}\text { Женский пол главы } \\
\text { домохозяйства }\end{array}$ & $1,944 * * *$ & 0,155 & $0,597 * * *$ & 0,040 & $3,369 * * *$ & 0,672 & $0,773 * * *$ & 0,068 \\
\hline $\begin{array}{l}\text { Возраст главы } \\
\text { домохозяйства }\end{array}$ & \multicolumn{8}{|c|}{ референтная группа - от 30 до 49 лет } \\
\hline до 29 лет & $1,666 * * *$ & 0,188 & $1,437 * * *$ & 0,129 & 1,087 & 0,225 & 0,944 & 0,098 \\
\hline от 50 лет и старше & $1,369 * * *$ & 0,125 & $1,567 * * *$ & 0,118 & $0,131 * * *$ & 0,041 & $0,239 * * *$ & 0,031 \\
\hline Москва/Санкт-Петербург & 1,202 & 0,158 & 0,839 & 0,111 & $0,470 *$ & 0,201 & 0,842 & 0,148 \\
\hline Тип населенного пункта & \multicolumn{8}{|c|}{ референтная группа - город } \\
\hline Село & $0,797 * *$ & 0,073 & $1,126^{*}$ & 0,080 & 1,045 & 0,206 & $1,176^{*}$ & 0,115 \\
\hline Федеральный округ & \multicolumn{8}{|c|}{ референтная группа -Центральный федеральный округ } \\
\hline Северо-западный & 1,221 & 0,178 & 1,096 & 0,143 & 1,257 & 0,413 & 1,294 & 0,208 \\
\hline Южный & $0,754 * *$ & 0,107 & 0,824 & 0,098 & 1,097 & 0,325 & 0,966 & 0,147 \\
\hline Приволжский & $0,809 *$ & 0,092 & 1,091 & 0,106 & 0,931 & 0,251 & 1,015 & 0,137 \\
\hline Уральский & 0,873 & 0,131 & $1,443 * * *$ & 0,170 & 1,124 & 0,370 & 0,765 & 0,146 \\
\hline Сибирский & $0,765 *$ & 0,106 & $1,208 *$ & 0,134 & 0,835 & 0,270 & 1,247 & 0,185 \\
\hline Дальневосточный & 0,813 & 0,171 & $1,346 * *$ & 0,193 & 0,422 & 0,261 & 1,311 & 0,257 \\
\hline Время начала перехода & 1,009 & 0,008 & $0,987 * *$ & 0,007 & 0,982 & 0,018 & $0,963 * * *$ & 0,008 \\
\hline $\begin{array}{l}\text { Лог общих расходов } \\
\text { домохозяйства }\end{array}$ & $\begin{array}{r}0,983 * * \\
*\end{array}$ & 0,004 & $1,032 * * *$ & 0,003 & 0,993 & 0,011 & $1,044 * * *$ & 0,006 \\
\hline Pseudo Log L & \multicolumn{2}{|c|}{$-5988,78$} & \multicolumn{2}{|c|}{$-8532,58$} & \multicolumn{2}{|c|}{$-1078,52$} & \multicolumn{2}{|c|}{$-4652,28$} \\
\hline
\end{tabular}

Примечания: * - $p<0,1, * *_{-} p<0,05, * * *-p<0,01$ 


\section{CHANGES IN THE STRUCTURE OF RUSSIAN HOUSEHOLDS IN 1994-2013 (STATISTICAL ANALYSIS)}

\section{KSENIYA ABANOKOVA}

KSENiYA Abanokova. National Research University Higher School OF Economics. E-MAIL: kabanokova@hse.ru. DATE RECEIVED: December 2015.

Comparing the family structure of the population and the composition of households is currently a topic of great importance. One of the problems with studying family composition is that most of the data used by demographers comes from census and other cross-sectional sources of information. Cross-sectional data provide only a single snapshot of family structure and do not allow for an analysis of changes within families over a period.

Individual transitions among different household types and duration of stay in a household of a given type are studied with the method of survival analysis using the Kaplan-Meier survival function. Analysis is based on the data of the panel study 'Russian Longitudinal Monitoring Survey' (RLMS) of HSE from 1994 until 2013.

RLMS data provide a unique opportunity to observe the same households over time, as well as the opportunity to fix all the changes in the household's state and the time of an event. The applied statistical methods make it possible to overcome the limitations associated with the character of RLMS panel data, as well as to evaluate the probability of a household's status change, taking into account the length of stay of individuals in households and the factors influencing this probability.

Although we do not study the causes of the observed distribution of households, because of their diversity and complexity of interpretation, our descriptive analysis provides a basis for further analytical study of the causes of the transformation of households.

Key words: household structure, panel data, survival analysis, Kaplan-Meir method, RLMS.

\footnotetext{
* This Work is an outPut of a ReSEARCh project implemented as a part of the Basic Research Program at the National RESEARCH UNIVERSITY HIGHER SCHOOL OF ECONOMICS. THESE ARE THE VIEWS OF THE AUTHOR, AND SHOULD NOT BE ATTRIBUTED TO THE HSE OR ANY AFFILIATED ORGANIZATION.
}

\section{REFERENCES}

Abanokova K., M. Lokshin (2015). Changes in household composition as a shock-mitigating strategy // Economics of Transition. 23(2): 371-388.

Fine J., R. Gray (1999). A proportional hazards model for the subdistribution of a competing risk. Journal of the American Statistical Association. 94: 496-509.

Golovlyanicina E. B. (2007). Rol`socialno-psihologicheskihfaktorov v reproduktivnyhnamereniyah// Roditeli I deti, muzhchiny I zhenshchiny v semi I obshchestve[The role of the social and psychological factors in reproductive intentions // Parents and children, men and women in family and society] / T.M. Maleva, O.V.Sinyavskaya, eds. NISP: 217-250.

Maleva T.M., O.V. Sinyavskaya (2007). Socialno-ehkonomicheskiefaktoryrozhdaemosti v Rossii: ehmpiricheskieizmereniyaivyzovysocial'nojpolitiki //Roditeli I deti, muzhchiny I zhenshchiny v semi I obshchestve[Socio-economic factors of birth rate in Russia: empirical 
measurements and challenges of social policy // Parents and children, men and women in family and society]/ T.M. Maleva, O.V.Sinyavskaya, eds. NISP:171-216.

Prokofeva L.M. (2007). Domohozyajstvo i semya: osobennosti struktury naseleniya v Rossii // Roditeli I deti, muzhchiny I zhenshchiny v semi I obshchestve[Household and family: the features of the structure of the population in Russia // Parents and children, men and women in family and society]/ T.M. Maleva, O.V.Sinyavskaya, eds. NISP: 251-266.

Roshchina Ya.M., A.V. Bojkov (2005). Faktory fertilnosti v sovremennoj Rossii // Rossijskij koncorcium ehkonomicheskih issledovanij i obrazovaniya. [Fertility determinants in modern Russia // Russian koncortsium Economics Education and Research]. Seriya «Nauchnye doklady». WP № 05/04.

Sinyavskaya O.V., S.V. Zaharov, M.A. Karceva (2007). Povedenie zhenshchiny na rynke truda i detorozhdenie v sovremennoj Rossii // Roditeli I deti, muzhchiny I zhenshchiny v semi I [The behavior of women in the labor market and childbirth in modern Russia // Parents and children, men and women in family and society]/ T.M. Maleva, O.V.Sinyavskaya, eds. NISP: 421-476.

Sinyavskaya O.V., A.O. Tyndik (2009). Rozhdaemost' v sovremennoj Rossii: ot planov k dejstviyam? [The birth rate in modern Russia: from the plans to actions?]// SPERO. 5: 131158.

Slonimczyk F., A.V. Yurko (2014). Assessing the impact of the maternity capital policy in Russia // Labour Economics. 30: 265-281.

Volkov A. G. (1986). Semya-obektdemografii[Family is an object of demography]. M: Mysl'.

Zaharov S.V. (2006). Vozrastvstupleniya v pervyjbrak//

DemograficheskayamodernizaciyaRossii, 1900-2000[Age of first marriage // Demographic modernization of Russia]/A.G. Vishnevsky, ed. M: Novoeizdatel'stvo.

Zaharov S.V. (2007). Transformaciyabrachno-partnerskihotnoshenij v Rossii: «zolotojvek» tradicionnogobrakablizitsya k zakatu? // Roditeli I deti, muzhchiny I zhenshchiny v semi I obshchestve[The transformation of marriage and partnerships in Russia: the "golden age" of traditional marriage is coming to a decline? // Parents and children, men and women in family and society] / T.M. Maleva, O.V.Sinyavskaya, eds. NISP: 75-126. 